\title{
Violentamente visual. Los límites de la representación de la violencia
}

\author{
Violently Visual. The Limits of the Representation of Violence
}

\author{
DANIEL INCLÁN \\ Posgrado en Estudios Latinoamericanos \\ Universidad Nacional Autónoma de México
}

RESUMEN: Este texto desarrolla la tesis de Susan Sontag sobre el cambio de las imágenes en el siglo XXI, donde se difumina la frontera entre representación y extensión de la violencia, que formula a partir de las fotografías de los soldados estadounidenses torturando musulmanes en Abu-Ghraib. Las imágenes de los cuerpos violentados que intentan "representar" la violencia pueden ser leídas como una manera de expandir lo que sucede en la clandestinidad al espacio público. Esto nos recuerda que toda violencia tiene un carácter semántico, que además de afectos sobre la piel, produce efectos sobre el sentido (entendido como sensibilidad, dirección y significación). Las formas de la violencia producen su propia estética, que se expande más allá de los momentos de ejercicio de una fuerza física. Esto es parte de una producción particular de la presencia, que da las condiciones de posibilidad de toda representación.

ABSTRACT: This text develops the thesis of Susan Sontag on the change of images in the XXI century, where diffuse the border between representation and extension of violence, which is formulated from the photographs of American soldiers torturing Muslims in Abu-Ghraib. The images of the violated bodies that try to "represent" the violence can be read as a way to expand what happens in hiding to the public space. This reminds us that all violence has a semantic character, which in addition to affect the skin, produces effects on the sense (understood as sensitivity, direction and meaning). The forms of violence produce their own aesthetic, which expands beyond the moments of exercise of a physical force. These are part of a particular production of presence, which gives the conditions of possibility of all representation.

PaLABRAS Clave: violencia, cuerpo, representación, estética de la violencia.

KEYWORDS: violence, body, representation, aesthetics of violence.

RECIBIDO: 9 de abril de 2018 • ACEPTADO: 23 de mayo de 2018. 



\section{DANIEL INCLÁN}

Posgrado en Estudios Latinoamericanos

Universidad Nacional Autónoma de México

\section{Violentamente visual.}

\section{Los límites de la representación de la violencia}

Aquí la moda ha inaugurado el lugar de intercambio dialéctico entre la mujer y la mercancía - entre el placer y el cadáver-. [...] Pues nunca fue la moda sino la parodia del cadáver multiforme, provocación de la muerte mediante la mujer, amargo diálogo en susurros, entre risas estridentes y ensayadas, con la descomposición.

El libro de los pasajes.

WALTER BENJAMIN

No la costumbre del veneno, sino la costumbre de la muerte; no la muerte domesticada, sino la doméstica; esta es la enseñanza de Mitrídates: para preservar la vida es necesario morir en dosis homeopáticas.

Sílabas negras. ANTONIO GAMONEDA

\section{El cambio visual}

En uno de sus últimos ensayos, Susan Sontag (2004), al hablar sobre las fotografías en las que se veía al personal al servicio de las fuerzas armadas estadounidenses torturando a detenidos musulmanes en Abu Ghraib, decía que: "The pictures taken by American soldiers in Abu Ghraib, however, reflect a shift in the use made of pictures - less objects to be saved than messages to be disseminated, circulated". ${ }^{\text {Para pensar }}$

1 "Estas imágenes tomadas por los soldados estadounidenses en Abu Ghraib, sin embargo, expresan un cambio en el uso de las imágenes: menos objetos de conservación que mensajes para ser diseminados, circulados". 
sobre este cambio en el uso social de las imágenes, es necesario pensar su vínculo con las transformaciones en el ejercicio de la violencia militar. Las fotos de Abu Ghraib no solo demuestran un cambio en la manera de producir y circular imágenes; son parte de un cambio radical en las formas de la violencia y en las posibilidades de su representación.

Desde 2001, las imágenes sobre la guerra contra el terrorismo, producidas por miembros de las fuerzas armadas estadounidenses y los grupos de mercenarios a su servicio, más que generar un testimonio, prolongaban por otros medios lo que sucedía tanto en los campos de batalla como en las actividades clandestinas. Uno de los objetivos era demostrar el carácter necesario de la guerra; al mismo tiempo que generar mensajes desmovilizadores dirigidos a los "enemigos terroristas", intentando ganar la guerra más allá de los campos de batalla. En el caso de las imágenes de las torturas, no representaban los abusos de los soldados, los extendían, los expandían a otros tiempos y espacios. Todo esto gracias a la portabilidad de los equipos de reproducción, al formato digital y a las redes sociales. Correlativa a la portabilidad de las armas. Este vínculo vuelve más evidente la relación del disparo, como activación de una cámara fotográfica y como activación de un arma de fuego (Sontag 2016).

La difusión de las imágenes de los abusos cometidos en la prisión clandestina diseminaba y disparaba la tortura y sus efectos por fuera de los lugares en los que los cuerpos eran lastimados, llegando a otros cuerpos en otras geografías. Al prolongar la tortura por medios visuales, las imágenes lograban dos objetivos complementarios dirigidos a públicos diferenciados. Por un lado, comunicaban, a aquellos enemigos reales o potenciales, el objetivo último de la guerra: degradar los cuerpos de los combatientes y con ello, ofender sus creencias, ridiculizar sus prácticas culturales y agraviar su historia. Los eufemismos intentaban limitar el peso de las imágenes, en lugar de tortura, se hablaba de técnicas agresivas de interrogatorio; en lugar de combatientes terroristas. Esta forma discursiva servía para ocultar el hecho de que la violencia sucedía fuera de toda convención internacional sobre los asuntos de la guerra. Con este procedimiento se intentaba justificar la degradación de los cuerpos y su historicidad; las posturas abyectas en las que se les colocaba construían una imagen de cuerpos dispuestos a todo abuso, 
porque eran literalmente vidas desnudas, ${ }^{2}$ desprovistas de todo orden de historicidad y de toda mediación ante la mirada de los otros.

Por otro lado, se buscaba ganar adeptos para legitimar una guerra que servía de máscara para el avance del control estratégico del Medio Oriente y de sus riquezas. Las imágenes de la guerra construyen un público de espectadores que pasivamente miran el despliegue exitoso de las fuerzas aliadas; al mismo tiempo, construye un público susceptible de padecer los efectos del poder destructor. Las fotos de Abu Ghraib son las fotos del pasmo: parálisis y sorpresa; dos condiciones necesarias para la contemplación pasiva de la guerra social que se expande por el mundo. Un espectáculo que se puede mirar con cierto goce estético o como una amenaza ante la que nada se puede hacer.

Finalmente, la diseminación de la violencia más allá de los lugares en los que los cuerpos eran abusados contribuía a la construcción de un tipo peculiar de sujetidad social: la del juez. De ser espectador del pasmo, se puede pasar a ser juez del contenido de las imágenes y de las motivaciones políticas que había detrás. Si la función del espectador construye la sensación de una distante cercanía, la del juez, permite aparecer como un actor sui géneris, cuyo objetivo es el de "dictar" sentencia y con ello sentir que se ha realizado algo ante la violencia que está frente a sus ojos.

A partir de estas fotografías se puede reconocer una época dominada por el fin de la representación. Las imágenes prolongaban la violencia, no la representaban. Esta mudanza abre la puerta para discutir un elemento poco analizado sobre las formas de la violencia: su dimensión estética y, por tanto, su extenso carácter comunicativo. ${ }^{3}$ Las formas de la violencia producen efectos sobre los cuerpos no solo en el momento de su ejecución; se prolongan más allá gracias a su carácter expresivo y a su operación pedagógica. La violencia construye semánticas y desde

\footnotetext{
2 "La nuda vida, es decir la vida a quien cualquiera puede dar muerte pero que es a la vez insacrificable" (Agamben, 1998: 18).

Rita Segato (2010 y 2014) es de las pocas estudiosas de la violencia que ha reconocido su carácter expresivo y su función disciplinaria, que ella califica como pedagogía de la crueldad. A excepción de Segato, los trabajos sobre la dimensión estética de la violencia atienden las producciones artísticas, por medio de las cuales se intenta construir contrarrelatos o narrativas que expliquen y critiquen la violencia que se produce como exterior a las obras.
} 
ella prácticas de disciplina social, que usan a los cuerpos violentados como dispositivos que sirven para organizar conjuntos más amplios de poblaciones, a través de una producción de sensibilidades y significaciones. En principio, se dirige a aquellos directamente vinculados con los cuerpos afectados (familiares, amigos, compañeros); pero también opera en las relaciones colectivas que esos cuerpos sintetizan (de género, de clase, de edad, de creencias, de prácticas políticas); así como las relaciones sociales circundantes, las que se piensan externas al conflicto, pero miran con morbo y miedo su realización.

La crítica que abre el ensayo de Sontag (que da continuidad a sus reflexiones sobre la ética y la política de la imagen desarrolladas en Ante el dolor de los demás) sirve para pensar el papel que juegan las imágenes en el ejercicio de la violencia y, más aún, sirve para pensar una crítica de la violencia desde sus dimensiones estéticas. Esto es necesario para poder construir reflexiones críticas sobre la representación de la violencia hoy. De continuar atendiendo solo al carácter formal de las imágenes de la violencia, sin pensar sus vínculos con las estructuras semánticas, no podremos salir del círculo que gira en torno a la representación imposible o a la representación prohibida; ambas, expresiones de un falso problema, que intenta resolverse resaltando la imposibilidad constitutiva de toda imagen de la violencia, en tanto que no hay experiencia que la soporte (un argumento reciclado sobre el vacío de imágenes del exterminio en las cámaras de gases en los campos de concentración nazis), o que busca resolverse por la vía de la restricción, prohibiendo, bajo argumentos morales o religiosos, toda posible imagen de los hechos violentos y sus efectos. $\mathrm{Ni}$ la imposibilidad ni la prohibición sirven para pensar el vínculo entre violencia e imágenes.

A pesar de este falso problema y sus insuficientes resoluciones, vivimos en un mundo de sobreabundancia de imágenes que intentan dar cuenta de la violencia. En particular en México, durante los últimos lustros, hay una sobreproducción de imágenes en los más variados soportes (visuales, literarios, gráficos, escultóricos, teatrales, danzísticos), para tratar de construir representaciones de la violencia que vive el país. El extenso acervo de imágenes cubre un amplio abanico de intenciones formales y políticas, desde aquellas producciones de pretensiones rea- 
listas, hasta aquellas que, con el uso de los más diversos tropos, tratan de construir escenas para dar cuenta de la violencia.

El mayor número de imágenes es el que tiene poco o nulo cuidado sobre las consecuencias políticas y éticas. Son las imágenes que todos los días aparecen en los periódicos de nota roja, en sus versiones nacionales o locales. En ellas se produce una anulación de la dialéctica de la mirada. El esquema exitoso para que la dialéctica de la mirada se cancele es el que junta en un mismo plano una imagen plagada de sangre junto a la imagen pornográfica de una mujer. Este modelo se extiende de las primeras planas de la nota roja a las pantallas de la televisión, que, mediante simulaciones, vinculan la violencia "criminal" con cuerpos exuberantes de mujeres. Este tipo de imágenes se complementan con aquellas construcciones moralizantes que contribuyen a un juicio generalizado que justifica la violencia: "Les pasó por algo". Acá los medios de comunicación dominantes tienen un rol estratégico; en su producción de imágenes ponen en juego los prejuicios conservadores, clasistas, machistas y racistas que permiten respuestas simples y fáciles.

Del otro lado hay un esfuerzo titánico por restituir la dialéctica en las imágenes y con ello su politicidad, contribuyendo a generar espacios de crítica social. El trabajo de la crónica ha sido muy importante en este terreno; la ruptura entre géneros periodísticos y literarios ha abierto espacios para mirar de otra forma la violencia. Estas narrativas de la violencia permiten la toma de la palabra, tanto de los desaparecidos o asesinados, como de sus vínculos cercanos (madres, hijas, parejas, amistades). Una primera operación para restituir la dialéctica ante la violencia ha sido la de volver a cultivar la palabra.

También la fotografía ha producido transformaciones en los lenguajes para dar cuenta de la violencia, superando el morbo de la nota roja y de las imágenes sin mediaciones. En estos ejercicios, se ve la violencia sin mirar descarnadamente, se reconoce por otros efectos, más allá de la sangre o los cuerpos abyectos. Se restituye la dialéctica al inscribir las imágenes de la violencia en contextos colectivos, demostrando que no es un problema de verdugos y víctimas, sino una compleja relación social.

Para poder ponderar los límites y los alcances de las imágenes, es necesaria una reflexión sobre los dos procesos que están en juego: tanto 
de lo que se intenta representar, como de los esfuerzos de representación, para entender qué vínculos mantienen entre sí y de qué maneras se pueden generar relaciones críticas que contribuyan a la reconstrucción y a la interpretación de las formas de la violencia.

\section{Estética de la violencia}

Al hablar de la dimensión estética de la violencia se hace referencia al ámbito de su ejecución, que afecta, altera o produce percepciones y sensaciones, un proceso que genera efectos sobre los cuerpos y la manera de percibirlos. No se refiere solo a aspectos formales; es, sobre todo, una relación entre cuerpos y las palabras que los configuran.

La estética es una forma de organizar el sentido y generar conocimientos en torno a situaciones sociales. Desde esta perspectiva, el sentido tiene una dimensión tripartita: sentido como dirección, como un telos de un determinado movimiento, que define un rumbo, sea provisional, frágil o consolidado. Por otro lado, sentido como sensibilidad, como la sistematización de informaciones que se produce por la "irritación" de las terminales nerviosas y que cimbra a los cuerpos por sus interacciones. Finalmente, sentido como significación, como la práctica de interpretación de una situación y sus posibles consecuencias, descifrando sus contenidos y sus articulaciones.

En la dimensión estética se despliegan los problemas sociales del sentido y su doble procedimiento: el que trabaja para la emancipación y el que consolida las subjetividades producidas por relaciones de poder. ${ }^{4}$ Por tanto, la estética no es el terreno exclusivo del arte; este sería una expresión estética colmada, saturada de intenciones de hacer estallar al

$4 \quad$ Terry Eaglenton señala con precisión el origen moderno de la estética como un discurso sobre los cuerpos. "Lo estético es a la vez el modelo secreto de la subjetividad humana en la temprana sociedad capitalista, y una visión radical de las energías humanas, entendidas como fines en sí mismos, que se torna en el implacable enemigo de todo pensamiento de dominación o instrumental; lo estético constituye tanto una vuelta creativa a la corporalidad como la inscripción en ese cuerpo de una ley sutilmente opresiva; representa, por un lado, un interés liberador por la particularidad concreta; por otro, una forma engañosa de universalismo" (Eaglenton 2011: 60). 
sentido mediante la producción de totalidades autónomas: un poema, una pintura, etcétera. La estética va más allá de lo artístico; no puede reducirse a esta esfera. Sobre todo si se quiere pensar su vínculo con la violencia.

La violencia, en tanto productora de sujetos y subjetividades, tiene una dimensión estética; contribuye a la organización de los sentidos de la vida social. Esto lo hace a través de estructuras de significación. ${ }^{5}$ La violencia produce discursos, no solo signos; enuncia relaciones de poder y con ellas capacidades discursivas, a través de las cuales se reorganiza el mundo lingüístico y extralingüístico; participan en la construcción de códigos y de procesos comunicativos.

Pensar la violencia desde su dimensión estética, como un proceso en el que se disputa el sentido, nos permite pensarla más allá de los actos en los que se verifica su existencia. Reducir el estudio de la violencia a los actos contribuye a una confusión generalizada a través de la cual se homologa la violencia con la ira o la agresividad; ambas pasiones concluyen en actos de fuerza cuyo fin es la destrucción simbólica o real de personas u objetos. En cambio, la violencia es un proceso de cálculo por medio del cual se intenta establecer una situación y su racionalidad usando una fuerza o un conjunto de fuerzas (físicas, cognitivas, afectivas). La violencia produce un entorno material y una semántica, que sirve para legitimar el acto y construir una racionalidad, por muy precaria que sea. Por tanto, no hay violencias irracionales; toda violencia tiene

Acá recupero la propuesta de Emile Benveniste para diferenciar el papel del signo y el discurso, la semiótica de la semántica, atendiendo la estructura social de significación y papel que el signo juega en la construcción de discursos históricamente determinados. "Con lo semántico entramos en el modo específico de significancia que es engendrado por el DISCURSO. Los problemas que se plantean aquí son función de la lengua como productora de mensajes. Ahora, el mensaje no se reduce a una sucesión de unidades por identificar separadamente; no es una suma de signos la que produce el sentido; es, por el contrario, el sentido concebido globalmente, el que realiza y se divide en 'signos' particulares, que son las PALABRAS. En segundo lugar, lo semántico carga por necesidad con el conjunto de referentes, en tanto que lo semiótico está, por principio, separado y es independiente de toda referencia" (Benveniste 1999: 67-68). El papel del discurso permite vincular, no sin dificultades, con Michel Foucault (2002), en especial con la diada enunciación-enunciado, en la que Foucault atiende al enunciado como el espacio de la experimentación dentro de un orden discursivo, en el que se despliegan las relaciones de poder que organizan los polos de la verdad y la pertenencia. 
la fuerza para generar sus razones y sus procesos de entendimiento, morales o cognitivos, aunque estos sean frágiles y limitados.

La violencia produce diferencias donde no existían, al tiempo que genera los mecanismos para controlarlas, prolongar su existencia y sus efectos. Es una operación de cálculo, que intenta articular un conjunto de acciones que afectan los cuerpos y las percepciones, los objetos y las interpretaciones. En la cual no se persigue la igualdad, sino la diferencia normalizada y la destrucción-construcción del sentido mediante la fuerza. La violencia reordena, establece legalidades que antes no existían. Por ello opera de maneras específicas; nunca es homogénea y nunca se aplica al conjunto de una población; es selectiva, sistemática y administra las fuerzas que la hacen posible. En tanto productora de diferencias, trabaja selectivamente; aunque construye una imagen omniabarcante, que en su apariencia parece afectar a todos por igual, esta percepción es resultado de la pedagogía de la crueldad con la que opera y los miedos que esta genera.

La violencia actúa, pero no es ahí donde está su esencia. Está en el intento de imponer un ordenamiento (sus efectos en cuerpo, objetos y percepciones) y en la construcción de sujetos. Produce dos tipos de subjetividades dinámicas: los ejecutores y los que experimentan sus efectos; en medio de estas aparecen otras dos: la de los espectadores y la de los jueces. No hay, por tanto, violencias universales, ni una forma genérica, sino formas de la violencia en las que se encadenan, de manera particular, actos, instrumentos, tiempos y espacios, todos inscritos en proyectos políticos determinados. Estas formas de la violencia trabajan en función de objetivos específicos, a veces articulados, a veces autónomos.

De ahí que toda la crítica de la violencia sea una crítica histórica, porque no es un acto universal, ni, mucho menos, una naturaleza social. "La crítica de la violencia es la filosofía de su historia” (Benjamín 2010). "La filosofía de su historia" exige preguntas por los fundamentos y por la manera en la que estos se configuran. Obliga a una lectura genealógica, que supere el análisis de los fenómenos de coyuntura y se pregunte por las relaciones de poder que hay detrás de las formas de la violencia.

Paralelamente, toda crítica de la violencia necesita ser una crítica política, ya que siempre opera en el marco de proyectos políticos; es aquí 
donde se puede reconocer su especificidad, no en los actos en los que se realiza (que pueden ser prácticamente los mismos desde hace siglos). Su historicidad no está en la novedad o continuidad de ciertas prácticas, sino en la manera en la que estas se articulan con proyectos políticos específicos, y cómo, dentro de estos, se construyen sujetos susceptibles de ser violentados.

Una manera de construir la crítica de la violencia puede ser a partir de su dimensión estética, como forma de salir de cuatro grandes trampas: 1) la cuantitativa, aquella que se obsesiona por los números como criterio de verdad; 2) la judicial, aquella que reconstruye los hechos para construir argumentos en una disputa legal, que reduce la mirada a un horizonte de víctimas-victimarios; 3) la testimonial, que, a contramano de las otras dos, construye al testimonio como un criterio suficiente para explicar los sucesos de la violencia; 4) la sociologizante, que concibe a la violencia como una anomia social, como una relación excepcional de las formas culturales.

\section{Los límites de la representación}

Toda representación se caracteriza por generar imágenes (ideales, visuales, auditivas) que producen distanciamiento, una relación que permite cierto grado de entendimiento de una situación dada. La representación no es suplantación de una realidad, ni una cosa que refiere a cosas; es un proceso (una mediación) a través del cual se hace inteligible el mundo. Los fines de la representación pueden ser dos, aunque contrapuestos: uno, el de reconstruir el orden de lo representado, y ratificar la estabilidad de una situación, su orden normativo y su materialidad; el otro puede ser el de destruir el orden de lo representado, poniendo en duda la estabilidad de la situación, cuestionándola con el fin de construir un espacio para las posibilidades. El distanciamiento que produce toda representación puede, por tanto, reconstruir o destruir, refundar o crear.

De ahí que el término sea polisémico y reapropiado por distintas prácticas sociales. Al menos hay tres grandes dimensiones. Aquella que refiere a la condición política moderna, en la que las instituciones estatales se presentan como la representación del poder popular que las 
funda. En este caso, la representación no es sino una forma de ocultar relaciones de poder, un reparto desigual de la politicidad social, que queda monopolizada por burocracias estatales y poderes fácticos. Un segundo nivel refiere al proceso productivo de discursos, en distintos soportes, a través de los cuales se intenta dar cuenta, con (cierto grado de criticidad) de un suceso o un conjunto de sucesos. En la representación como producción se ponen en juego las capacidades de entendimiento de una realidad y la creatividad para traducirla en otros códigos. Por último, hablar de representación tiene un carácter performativo, en el que la actividad teatral es su mejor expresión, pero también incluye a los performances y los happenings. En esta dimensión, representar presupone una puesta en escenas de situaciones, concretas, imaginarias, reales o potenciales, a través de las cuales se produce una relación de extrañamiento con el mundo.

En estos tres niveles, la representación está en crisis, resultado de dos procesos combinados. Aquel que refiere al límite las maneras de entendimiento y acercamiento a la realidad, y con ellas el desuso de las capacidades refractarias de entenderla (a través de tropos que funcionan como estrategias epistémicas: la metáfora, la alegoría, las sinécdoques, etcétera). El mundo hiperrealista en el que vivimos limita las estrategias de distanciamiento, propio del realismo capitalista que se ha convertido en criterio estético universal. ${ }^{6}$ Esto es parte del triunfo del fetichismo de la mercancía, que produce un mundo organizado por apariencias, mediado por imágenes que encubren la violencia constitutiva de los objetos con los que interactuamos en todo momento. ${ }^{7}$ El correlato del realismo capitalista es la estetización obscena del mundo, vivir rodeados de objetos

6 "El realismo capitalista no puede limitarse al arte o al modo casi propagandístico en el que funciona la publicidad. Es algo más parecido a una atmósfera general que condiciona no sólo la producción de cultura, sino también la regulación del trabajo y la educación, y que actúa como la barrera invisible que impide el pensamiento y la acción genuinos" (Fisher 2016: 41). En este ambiente se genera una impotencia reflexiva, en la que no aparecen en el horizonte salidas al mundo corporativo del capitalismo contemporáneo.

7 Guy Debord (2010) anunció desde hace más de medio siglo los límites de la representación en un mundo de fetiches; en años recientes el grupo Krisis recuperó los planteamientos de Karl Marx para explicar el papel del fetichismo y el dinero en la sociedad contemporánea. Estas ideas han sido complementadas por Anselm Jappe (2011) y Anselm Jappe, Robert Kurz y Claus Peter Ortlieb (2014). 
bellos, donde el valor de uso se reduce a puro ornato y donde la relación entre los cuerpos se hace de la misma manera que el consumo en serie, impersonal y anónimo de mercancías.

El otro proceso que define la crisis de la representación es el de los límites de la presencia. Aceptemos la idea de Jean-Luc Nancy (2006): la representación es la presentación de la ausencia que constituye toda presencia, es decir, del proceso que logra exponer (en su doble sentido: hacer visible y poner en riesgo) el vacío constitutivo de toda presencia, que nunca se muestra como completa (toda presencia es incompleta; de ahí su historicidad y su movimiento). La representación trabaja sobre esa falta constitutiva de toda presencia.

¿Qué pasa en una época en la que a la presencia de cuerpos se le niega todo el orden de presencia? ¿Qué tipo de presencia se produce cuando miles de cuerpos son asesinados en un orden de clandestinidad-pública? ¿Cómo son y están los cuerpos cuando interactúan entre sí como mercancías dispuestas a ser consumidas de las más diversas formas (como objetos de goce en una cadena sin límites de intercambios deserotizados, el give me more de la pornografía secularizada; como fuerza de trabajo espectral, que en el mercado de los servicios encuentra su plena realización al vender tanto las capacidades productivas como los sentimientos; como realidades desmontables en el mercado de órganos)? ¿Qué es lo que está presente en un mundo de simulacros y fetiches?

¿Cómo representar los cuerpos que son resultado de violencias anónimas, clandestinas o seriales? Aunque existan restos que pueden servir como índice de un cuerpo, son fragmentos desde los que es muy difícil pensar a la persona y sus relaciones colectivas (nombre, identidad, situación social, historicidad). Estamos ante proyecciones de lo que un cuerpo era, es decir, estamos ante fantasmas, sombras de aquello que se ha escapado de la conciencia del tiempo colectivo. Ante esto, el tema del espectro aparece, ya no como figura retórica, sino como problema filosófico e historiográfico. La representación tiene que lidiar con la forma de presencia producida por la violencia para poder dar cuenta del cuerpo ausente y no prolongar la violencia que lo borra.

Con estas interrogantes tiene que lidiar la representación hoy, no solo con los límites de sus procedimientos y artefactos, no solo con los límites de las imágenes, no solo con las fallas de los órdenes discursivos. El 
reto de la representación hoy es el problema de la presencia; y con ello, el papel central que juegan las formas de la violencia en su producción.

Acá está parte del nudo problemático sobre las imágenes de la violencia. En el caso mexicano, el debate ha girado en torno a una moral de la imagen o a una restricción de tipo político. La censura sobre los efectos de la violencia y su cobertura mediática produjo la patética firma del Acuerdo para la Cobertura Informativa de la Violencia (2011), a través del cual se intentaba "no interferir en el combate a la delincuencia, dimensionar adecuadamente la información y no convertirse en voceros involuntarios". Eufemismos para ocultar la censura gubernamental y la moral conservadora detrás de los monopolios mediáticos.

Esta política de comunicación tiende un velo sobre los problemas de fondo, sobre el tipo de relaciones sociales que hacen posible la violencia y sobre el tipo de corporalidad y presencia que se produce. La intención de comunicar los efectos de la violencia empata con lo señalado por Sontag: no estamos ante una representación de la violencia, sino ante su prolongación por medio de imágenes, que son parte de toda una compleja semántica. ${ }^{8}$ El problema en México no es de representación; es la presencia que produce la violencia, su manera de extenderse más allá de los momentos de su ejecución material, prolongándose por medio de imágenes que refuerzan la estructura semántica. Porque los cuerpos también están hechos de palabras y significaciones. Es aquí donde la violencia se constituye como la vía socialmente válida para producir presencias, en su doble dimensión: material y significativa.

Los cientos de imágenes (fotografías, dibujos, crónicas) que diariamente circulan en las calles del país, intentando dar cuenta de la violencia y sus efectos, voluntaria o involuntariamente prolongan la violencia, construyendo canales comunicativos a través de los cuales se disemina la pedagogía de la crueldad y contribuyen a la consolidación de una cultura del horror. Al carácter formativo que socialmente hay que enfrentar ante el avance de miles de cuerpos asesinados con saña, de cor-

Rossana Reguillo ha calificado a las nuevas doxas como narcoñol, una jerga llena de neologismos propios del código criminal, que se diseminan en la vida cotidiana hasta convertirse en una lengua franca, que se usa con pasmosa frialdad para hablar de los fenómenos de la violencia, expulsando todo esfuerzo por construir explicaciones complejas (Reguillo, 2011). 
poralidades mercantilizadas por diversos procesos, de corporalidades espectrales de las que solo quedan recuerdos colectivos o individuales porque no hay restos ni rastros; hay que sumar la pedagogía que se soporta en imágenes. "Se instalan tiempos sombríos, cuyo origen y causa no atinamos a identificar porque el sufrimiento causado nos parece que se exhibe y manifiesta exclusivamente en los otros" (Segato 2014: 46).

La estética de la violencia produce una anestesia social, la sobreproducción de imágenes, el inconmensurable dolor, la inexplicable desesperanza, la gratuidad de la muerte, producen dos efectos de parálisis: la que genera el miedo (hasta el patetismo de tener miedo del miedo) y la que resulta de la indiferencia y el olvido (como dos mecanismos de sobrevivencia). La anestesia social es inversamente proporcional al dolor de los cuerpos torturados; mientras más dolorosos y crueles son las formas de la violencia sobre los cuerpos, más insensible se vuelve la sociedad ante estos sucesos, a tal punto que la indiferencia se expande hasta las situaciones más cercanas y cotidianas (los maltratos a los niños en las plazas públicas; los insultos entre personas que se conocen). Esto no sería posible sin el extenso carácter comunicativo de las violencias y el papel que las imágenes juegan en ello. Es en este hiato donde se juega la representación, no en los límites morales o las incapacidades creativas.

\section{Cierre: lo político de la imagen}

En 1965, en un encuentro de cineastas reunidos para discutir el vínculo entre las formas creativas del nuevo cine y su compromiso político, Glauber Rocha (2011) leyó un manifiesto estético y político titulado "Estética del hambre", que también circuló como "Estética de la violencia". En este texto, Rocha anuncia dos ideas centrales para el tratamiento de las imágenes sobre la miseria y la violencia propia de los países periféricos, presas de formas renovadas de colonialismo. En principio, reconocía, que no se puede producir goce estético a partir de la miseria de los otros, como hasta entonces lo hacía el cine europeo, que intentaba representar la realidad colonial o poscolonial, lo mismo que cierto cine periférico, que, con intenciones de ganarse espacios en el circuito internacional del arte, generaba formas acordes con las estéticas mise- 
rabilistas, en las que se estetizaban las formas de la vulnerabilidad. Una segunda idea llamaba al compromiso colectivo para que los afectados produjeran sus imágenes, para que ellos mismos construyeran las representaciones en las que se pudieran reconocer, más allá de las modas o cánones formales. Dos procesos para que se pudiera restituir la historicidad de su humanidad robada, al saberse despojados por condiciones determinadas, al reconocerse como afectados por un sistema social que los construye como excresencia. A partir de esto, construir caminos de fuga hacia otro mundo.

No lucrar con la imagen del dolor de los otros y construir espacios sociales para que los afectados generen sus imágenes son dos de las conclusiones vigentes del ensayo de Rocha. Construir representaciones con estos compromisos tendría que ayudar a generar objetos hacia los que se dirija la furia social, que la ira se encamine hacia aquellos procesos que hacen posible la violencia, hacia aquellas prácticas que degradan la vida y convierten a los cuerpos en valores de uso hiperdegradados. Lo político de la representación no debería hipotecar su efectividad a la estetización, ni a la circulación en un amplio mercado de imágenes; debería regresar a lo más inmediato, a lo más próximo. Las representaciones, entonces, trabajarían para que la corporalidad y la presencia vuelvan a estar en nuestras manos: tener vida en nuestras manos y ser vida en manos de otro, no como mercancías de usos desechables, sino como formas históricas de existencia en las que están en juego las más amplias posibilidades de ser y estar en el mundo.

\section{Bibliografía}

Agamben, Giorgio (1998). Homo sacer. El poder soberano y la nuda vida. Valencia, Pre-textos.

Benjamin, Walter (2010). Crítica de la violencia, trad. Eduardo Maura. Madrid, Biblioteca Nueva.

Benveniste, Emile (1999). Problemas de lingüística general II. México, Siglo XXI.

DeBord, Guy (2010). La sociedad del espectáculo. Madrid, Pre-textos. EAGLETon, Terry (2011). La estética como ideología. Madrid, Trotta. 
FISHER, Mark (2016). Realismo capitalista. ¿No hay alternativas? Buenos Aires, Caja Negra.

Foucault, Michel (2002). La arqueología del saber. México, Siglo XXI.

JAPPE, Anselm (2011). Crédito a muerte. La descomposición del capitalismo y sus críticos. Logroño, Pepitas de Calabaza.

JAPPE, Anselm, Robert KuRZ y Claus Peter ORTLIEB (2014). El absurdo mercado de los hombres sin cualidades. Ensayos sobre el fetichismo de la mercancía. Logroño, Pepitas de Calabaza.

NANCY, Jean-Luc (2006). La representación prohibida, seguido de La Shoah, un soplo. Buenos Aires, Amorrortu.

Reguillo, Rossana (2011). "La narcomáquina y el trabajo de la violencia: apuntes para su decodificación", en E-misférica, 8.2 \#narcomachine, $<$ http://hemisphericinstitute.org/hemi/es/e-misferica-82/reguillo>, consultado por última vez el 12 de mayo de 2017.

Rocha, Glauber (2011). "Eztetyka del hambre", en La revolución es una Eztetyka. Buenos Aires, Caja Negra.

Segato, Rita (2010). Estructuras elementales de la violencia. Buenos Aires, Prometeo.

Segato, Rita (2014). "Las nuevas formas de la guerra y el cuerpo de las mujeres", en Sociedade e Estado, vol. 29, núm. 2: 341-371.

SontAG, Susan (2004). "Regarding The Torture of Others", en The New York Times Magazine, 23 de mayo de 2004, <http://www.nytimes. com/2004/05/23/magazine/regarding-the-torture-of-others.html?_r=0>, consultado por últi-ma vez el 29 de abril de 2017.

SonTAG, Susan (2012). Ante el dolor de los demás, trad. Aurelio Major. Madrid, Debolsillo.

Sontag, Susan (2016). Sobre la fotografía (trad. Carlos Gardini). México, Debolsillo.

UNESCO (2011). Acuerdo para la Cobertura Informativa de la Violencia. México, <http://www.unesco.org/fileadmin/MULTIMEDIA/HQ/CI/CI/pdf/ media_standards/Art\%2019\%20memorandum\%20on\%20the\%20mexican\%20draft\%20federal\%20act\%20Acuerdo_Medios_23_marzo_2011. pdf>, consultado por última vez el 10 de mayo de 2017. 